Voix et Images

voixetimages

\title{
Le blanc maléfique
}

\section{Jean-François Chassay}

Volume 19, numéro 1 (55), automne 1993

Lionel Groulx écrivain

URI : https://id.erudit.org/iderudit/201080ar

DOI : https://doi.org/10.7202/201080ar

Aller au sommaire du numéro

\section{Éditeur(s)}

Université du Québec à Montréal

\section{ISSN}

0318-9201 (imprimé)

1705-933X (numérique)

Découvrir la revue

\section{Citer cet article}

Chassay, J.-F. (1993). Le blanc maléfique. Voix et Images, 19(1), 200-204.

https://doi.org/10.7202/201080ar d'utilisation que vous pouvez consulter en ligne.

https://apropos.erudit.org/fr/usagers/politique-dutilisation/ 
Roman

\section{Le blanc maléfique}

Jean-François Chassay, Université du Québec à Montréal

Souvent associée à la pureté, à l'espérance, connotée de manière généralement positive, la couleur blanche révèle parfois davantage d'ambivalence. Dans Les Aventures d'Arthur Gordon Pym ${ }^{1}$, Edgar Allan Poe conduisait son héros éponyme vers la blancheur infinie de l'océan polaire, où il périssait en voyant un être dont "la couleur de la peau [...] était de la blancheur parfaite de la neige” p. 294): Quinze ans plus tard, un autre roman américain approfondira l'ambiguité. Il s'agit bien sûr de Moby $D i c k^{2}$, dans lequel le narrateur Ishmaël 
manifeste son épouvante devant la blancheur de la baleine. De là ce long développement sur l'ours blanc et le requin blanc, le suaire et les fantômes, le cheval de l'Apocalypse, qui viennent faire contrepoids au symbole des choses spirituelles et à la noblesse emblématique souvent conférée par cette couleur.

On pourrait lire dans les deux romans dont il sera question ici, à des degrés divers, une réactualisation de cette ambiguité. La blancheur devient synonyme de beauté et d'attirance mais aussi de danger et de perte. De la quête du territoire à celle de l'absolu, elle devient d'abord et avant tout signe d'un doute souverain dont la mort est l'aboutissement.

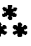

C'est vers le Nord ${ }^{3}$, un Nord mythique, fantasmé, synonyme également d'une blancheur morbide recouvrant tout, que conduit le troisième roman de Pierre Gobeil, Dessins et Cartes du territoire ${ }^{4}$. Comme dans son roman précédent, La Mort de Marlon Brando, la narration est laissée à un enfant. Ou, plutôt, à des enfants, puisque le "nous * narratif englobe deux frères qui se souviennent de leur aîné, profondément admiré, qui un jour, sans prévenir personne, décide d'abandonner l'île où résident ses parents, attiré vers le Nord, là où *il n'y a que le ciel et la neige. (p. 40). Tout le roman tient dans l'attente d'un possible retour, pendant lequel les deux frères se remémorent celui qui est parti. Ces scènes sont entrecoupées des propos et des espoirs de ce dernier: "Je crois, parce que les truckers l'ont dit, qu'il y a là-bas au nord un espace immense et propre où le vent est libre et où les rires se multiplient sur la glace. (p. 135). Retour improbable cependant, puisqu'on apprend, à la fin du roman, que cinq années se sont déjà écoulées depuis qu'il a pris la route sans donner de nouvelles.

Ce parcours aléatoire entraîne l'adolescent (surnommé Ti-Lou) vers un lieu qui voit l'abolition des frontières: *le ciel et la terre, c'est pareil . (p. 40). On peut se perdre dans cette immensité, là où "la terre est blanche comme le ciel est blanc", sans avoir de compte à rendre à personne. Il s'agit d'abord pour lui d'échapper à cette "petite île d'Amérique, [...] semblable à toutes les petites îles en Amérique. (p. 116) qu'il habite. L'attrait du continent est trop fort pour l'insulaire.

Ce désir des grands espaces s'incarne dans un individu chez qui on peut deviner, en palimpseste, les grandes figures du roadbook, le 
célèbre Dean Moriarty en tête: "Il était fou et sauvage; il aimait les routes et les camions. Son rêve, c'était de prendre un moteur et d'en nettoyer une à une toutes les pièces. Son rêve était de rouler du matin au soir, toute la journée, toute la nuit..." (p. 74); "Quand tu découvrais quelque chose, tu nous le disais et tu nous avais fait faire le tour du monde dans une Buick volée" (p. 88).

Le Nord se substitue à l'Ouest, la toponymie révèle des appellations françaises et inuit plutôt qu'anglaises et sioux - Sainte-Mariede-l'Estropié, Prêtre-Gelé, Whapmagoosti, Kuujjuaq - mais il s'agit bien du même rêve d'épuisement de l'espace territorial, la volonté d'atteindre un point précis où il $\mathrm{y}$ aurait parfaite adéquation entre l'individu et le territoire.

Cette coïncidence avec un large pan de la fiction étatsunienne depuis plus de trente ans est redoublée par la présence de la télévision américaine à laquelle se réfèrent souvent les deux frères. À l'orée des grands espaces, .c'est pourtant à travers celui, réduit, de l'écran de la télévision que les deux enfants conçoivent la réalité. Les films de Walt Disney permettent tous les espoirs: "Nous avions déjà vu tellement de films où celui qui était parti revenait que nous nous étions mis à croire, avec les autres, qu'il allait écrire une lettre pour dire qu'il allait rentrer" (p. 13). Le rêve américain de Kerouac est l'envers de celui de Disney. Le premier pousse à réaliser ses rêves (à ses risques et périls), alors que le second suggère que le rêve se résume à la routine quotidienne: "Ce que nous n'avions pas, nous l'avions vu à la télévision et le plus. souvent ce que nous voyions à la télévision nous était arrivé" (p. 119). Dans cet univers sans surprise, l'antenne parabolique fait partie du décor quotidien. À la naïveté de Ti-Lou correspond l'aliénation de ses deux frères pour incarner, au fond, une semblable solitude.

La vacuité de l'existence des jeunes frères, entièrement tournés vers le souvenir de l'aîné, s'exprime par une prose répétitive, incantatoire. La mélancolie qui s'en dégage cependant, parfois poignante, n'empêche pas que s'installe à la longue, à la lecture, une certaine lassitude, provoquée par une rhétorique un peu mécanique.

Comme Pierre Gobeil, Sylvain Trudel vient de faire paraitre son troisième roman. Et comme dans Dessins et Cartes du territoire, il s'agit de raconter un voyage, qui prend toutefois une toute autre direction (dans tous les sens du terme). Le Souffle de l'Harmattan et Terre du roi Christian, parus respectivement en 1986 et 1989, avaient été reçus avec beaucoup d'enthousiasme. Quatre ans plus tard, la parution de Zara ou la mer Noire ${ }^{5}$ déçoit un peu. 
Zara ou la mer Noire est le journal d'un jeune homme, mort à 27 ans de leucémie. Le manuscrit se retrouve entre les mains de celui qui fut, à une certaine époque, son "maître spirituel". Ce dernier, pour attirer l'attention, s'était transformé pour quelques semaines pendant ses années d'école en gourou, créant autour de lui une véritable secte (un des adhérents se prenait même pour la réincarnation d'Albert Camus et répétait sans cesse: "Je suis né dans un accident de voiture "...). Pris de panique devant son propre pouvoir, il décide de laisser tomber assez rapidement ce qui pour lui n'était qu'un jeu. Pour un des étudiants qui subira son influence pourtant, la vie deviendra une quête d'absolu. Son journal, annoté par le narrateur, raconte ce parcours initiatique qui le conduira, à travers moult détours, jusqu'au bord de la mer Noire.

La blancheur est représentée symboliquement ici par la recherche assoiffée de sainteté qu'exprime le jeune homme au fil des pages. Mais la prophétie qu'il proclame - il affirme qu'il mourra assassiné par une femme blanche - peut avoir un sens métaphorique, comme le note le narrateur: l'étymologie du mot leucémie, maladie qui l'emportera finalement, renvoie au grec leukos qui signifie "blanc". Mais l'ambiguité de la blancheur s'exprime également par l'oscillation constante entre sainteté et satanisme qui marque son itinéraire. Les meilleures pages du roman sont sans doute celles où cette tension entre les deux pôles de l'absolu provoque une véritable crise chez l'auteur du journal. Ce qui jusque-là pouvait apparaître comme les propos d'un esprit fanatique devient l'évocation d'une conscience déchirée, en proie aux doutes: "Comment être sûr de soi quand le corps et l'esprit sont les débris d'un royaume désagrégé?» (p. 39).

Cependant, l'introspection constante, l'érudition bibliophilique, laissent peu de place à ces tensions pour s'exprimer et elles ne parviennent pas souvent à s'incarner dans des événements signifiants. C'est le cas pourtant au moment de la mort du père, lorsque le jeune homme doit prendre l'avion pour retourner chez lui dans le but d'assister à l'enterrement et décide à la dernière minute de ne pas partir; c'est le cas également lorsqu'il vole un homme qui a agi avec lui par pure bonté. Dans ces scènes, la complexité de la quête se révèle dans toute son ampleur. Dans Terre du roi Cbristian, l'érudition s'intégrait davantage au texte et la présence incessante de la mort, aussi forte que dans ce dernier roman, n'était pas simple commentaire comme c'est trop souvent le cas ici.

Ce roman se situe dans le droit fil des précédents, formant un univers de plus en plus singulier et dont il n'y a pas d'équivalent au 
Québec. Après Le Souffle de l'Harmattan, on a souligné l'influence possible de Ducharme, ce qui était un compliment; Trudel semble maintenant avoir pris ses distances face à ses modèles les plus immédiatement repérables. Sauf que Zara ou la mer Noire a conduit Sylvain Trudel à un cul-de-sac. Certes, il n'y a pas de définition stricte du roman et il serait oiseux d'en proposer une idoine ici, à laquelle l'auteur devrait se conformer. Il reste cependant que Trudel ne renouvelle pas ce qu'on pouvait lire dans les deux romans précédents. Il ne fait "qu'appesantir" ses propres procédés, les poussant jusqu'à la caricature. La sainteté est parfois très très lourde à supporter dans Zara ou la mer Noire. On peut espérer qu'il s'agisse d'un roman de transition.

1. Edgar Allan Poe, Les Aventures d'Arthur Gordon Pym, Paris, Gallimard, coll. *Folio, 1973, $310 \mathrm{p}$.

2. Herman Melville, Moby Dick, Paris, Le livre de poche, 1965, 703 p.

3. Nord mythique qui, par les temps qui courent, jouit décidément d'un fort courant de popularité. Voir à ce propos la dernière chronique de Michel Biron, «Du Nord au Sud *, Voix et Images, $\mathrm{n}^{\circ}$ 54, printemps 1993, p. 610-614.

4. Pierre Gobeil, Dessins et cartes du territoire, Montréal, l'Hexagone, coll. *Fictions *, 1993, $138 \mathrm{p}$.

5. Sylvain Trudel, Zara ou la mer Noire, Montréal, Les Quinze, éditeur, 1993, 126 p. 